\title{
Recuperación de secuencias de información audiovisual con rdf y smil
}

\author{
Por Jorge Caldera-Serrano y Rodrigo Sánchez-Jiménez
}

\begin{abstract}
Resumen: Se presenta una propuesta para la marcación y recuperación de información audiovisual basada en secuencias aplicada a la gestión de información en televisión. A partir del análisis de la información audiovisual televisiva, se genera un vocabulario de marcado para agilizar y mejorar la recuperación de información. Este vocabulario proporciona acceso directo a las secuencias según parámetros específicos, como la diferenciación entre información visualizada e información referencial, lo que proporciona un marco de trabajo más adecuado para el dominio de la documentación audiovisual.

Palabras clave: Archivos de televisión, Información audiovisual $\square$ Esquema rdf, Smil, Recuperación de imágenes, Descripción de imágenes.

\section{Title: Audiovisual sequence based retrieval us-} ing rdf and smil

Abstract: In this article we present a proposal for sequence based audiovisual markup and retrieval which can be applied to information management in television. To achieve this we analyze and study audiovisual information on $T V$, and from this knowledge we generate a vocabulary for markup which might ease and improve information retrieval, providing direct access to sequences according to parameters such as distinguishing among visualized information and referenced information, which provides a working framework better adapted to the domain of audiovisual documentation.
\end{abstract}

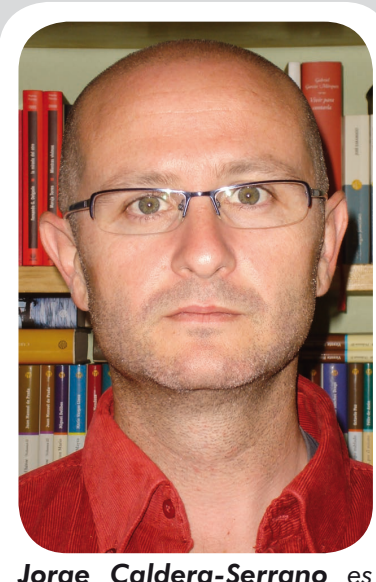

Jorge Caldera-Serrano es profesor en la Facultad de biblioteconomía y documentación de la Universidad de Extremadura, donde imparte docencia sobre archivos de televisión, filmotecas y fuentes de información audiovisual. Es licenciado y doctor en documentación por la Universidad de Salamanca. Autor de manuales, monografías, capítulos de libros y artículos, cuenta con estancias en diferentes países latinoamericanos.

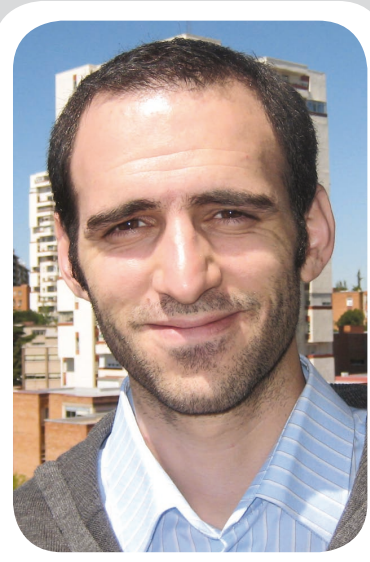

Rodrigo Sánchez-Jiménez es profesor del departamento de biblioteconomía y documentación de la Universidad Complutense de Madrid. Imparte docencia en materias de documentación informativa, documentación multimedia y técnicas de recuperación de información. Ha participado en varios proyectos de investigación y es autor de artículos sobre lenguajes documentales, gestión de la información y documentación audiovisual y multimedia.

Keywords: TV archives, audiovisual information, Rdf schema, Smil, Image description, Information retrieval.

Caldera-Serrano, Jorge; Sánchez-Jiménez, Rodrigo. "Recuperación de secuencias de información audiovisual con rdf y smil”. El profesional de la información, 2009, mayo-junio, v. 18, n. 3, pp. 291-299.

DOI: 10.3145/epi.2009.may.06

\section{Objeto de estudio y objetos del trabajo}

Las tecnologías de la información y la comunicación son parte fundamental de unas renovadas Ciencias de la Información. Su evolución ha dado lugar a cambios en la concepción y la práctica de la gestión documental. La digitalización de productos y servicios ha generado una mayor accesibilidad informativa y rapidez comunicadora que agiliza la labor de producción empresarial y documental. Se muestra el potencial de evolución del tratamiento de la información en las televisiones que puede provocar la inclusión de lenguajes de marcado específicos, lenguaje de marcado xml y de herramientas derivadas como rdfs y smil.

En la actualidad el gestor de información sigue trabajando con información referencial durante el proceso de análisis a pesar de la digitalización progresiva de las televisiones. Los departamentos de documentación hacen posible que la recuperación de información se traduzca no sólo en una información referencial sino en la recuperación del documento audiovisual, ya sea en su totalidad o en fragmentos de imágenes concretos.

En el tratamiento de material audiovisual es necesaria la traducción a un lenguaje textual de lo visionado para poder realizar las labores clásicas de condensación e indización. No obstante, hemos de señalar una serie de matizaciones:

- La descripción de secuencias es una práctica habitual en las televisiones que tienen infraestructuras y recursos humanos que lo hacen posible. Cuando no es así, lo que suele ocurrir en televisiones locales y otras 
con escasez de recursos, la descripción de secuencias es sustituida por la descripción única del contenido del documento audiovisual, la cual no siempre incluye una descripción exhaustiva y pormenorizada de los códigos de tiempos parciales.

- En la información temática, onomástica, cronológica y geográfica no relacionada con la banda imagen, los términos de indización no están asociados por lo general a una secuencia determinada, sino al documento completo. Ante este problema que se traduce en una dificultad de identificación de elementos en las secuencias, se ha demostrado que la consulta sobre el texto libre de la descripción de secuencias es más acertada y precisa en los elementos recuperados.

- Otra cuestión a tener en cuenta es que, debido a lo complicado de la descripción de las imágenes, la recuperación en texto libre y sobre lenguaje controlado se realiza de forma conjunta, ya que ambas pueden ser complementarias, refinando de forma precisa los elementos de la búsqueda.

Partiendo de la especificidad del documento audiovisual televisivo, se observa que en la forma del tratamiento e indización existe una duplicidad que puede ser paliada utilizando un marco común para la descripción de documentación audiovisual.

Para comprender la labor documental se va a tratar de explicar cómo se trabaja en descripción de contenido en las televisiones para, desde este conocimiento, plantearnos el siguiente paso: llevar a cabo la descripción de secuencias y la indización utilizando un único marco descriptivo estructurado que permita además la recuperación por secuencias de manera eficaz.

¿Cómo puede llevarse a cabo este objetivo? Partiendo de una correcta descripción de secuencias y utilizando las tecnologías de la Web semántica de forma eficaz. En la descripción, se van describiendo en texto libre todas las secuencias o conjunto de secuencias de un material audiovisual televisivo, constituyéndose, desde el punto de vista de su almacenamiento y tratamiento para la recuperación, en entidades separadas. Por ejemplo, una persona presente en la descripción de secuencias estará en el campo normativo onomástico destinado para tal efecto y viceversa (válido igualmente para temas y lugares).

$$
\begin{aligned}
& \text { "Existen parámetros comúnmente } \\
& \text { aceptados por la comunidad audiovisual } \\
& \text { televisiva, aunque no por la masa crítica } \\
& \text { investigadora" }
\end{aligned}
$$

\section{Descripción de contenido en televisión: estado de la cuestión.}

En la actualidad es utópico intentar mostrar una realidad única en la forma de trabajo y gestión de los departamentos de documentación de las televisiones, ya que existen parámetros que lo imposibilitan:

- hábitos adquiridos

- recursos humanos y económicos

- forma de entender la gestión de la información

- elementos tecnológicos propios de la gestión de la información audiovisual

- proceso de producción y explotación de las cadenas televisivas.

Sí existen parámetros comúnmente aceptados por la comunidad audiovisual televisiva, aunque no por la masa crítica investigadora. La investigación empresarial y la realizada en centros universitarios se encuentran muy alejadas, sobre todo por lo complicado de acceder a los desarrollos de las cadenas televisivas.

Tras el estudio de televisiones diversas por su origen geográfico y titularidad se puede extraer una serie de parámetros comunes.

Las etapas del tratamiento documental pueden sistematizarse en las siguientes (Caldera, 2006):

\section{"Las etapas del tratamiento documental en televisión son: visionado, descripción de imágenes e indización"}

- Visualización. Momento en el que se realiza la selección, así como la determinación de la unidad documental. Para ello debe visualizarse el documento en su totalidad y determinar aquellos elementos pertinentes, ya sea en una secuencia concreta o en el conjunto del documento. Aunque esta primera etapa está estrechamente relacionada con la identificación y selección del material y por lo tanto estaría enmarcada más en una etapa de la cadena documental que en un eslabón del tratamiento, la realidad de las televisiones con escasez de personal y mucho trabajo hace que en este primer visionado se realicen tareas de descripción, fundiéndose y confundiéndose en muchos casos con la etapa de descripción de imágenes que se describe a continuación.

- Descripción de imagen. En esta etapa se identifican los planos, movimientos de cámara y el desarrollo de la acción en texto libre, tanto de la banda visual como de la sonora. Esta fase es única en gestión 
documental, tan sólo utilizada para el tratamiento de la información audiovisual televisiva. Esta labor es la más complicada para el gestor de la información ya que consiste en transcribir la información audiovisual a un lenguaje textual que será su sustituto. Este ejercicio es una tarea de identificación de iconos, personas, entidades, lugares y la significación que sobre ellos da el conjunto de la información.

Un ejemplo de descripción de secuencias sería el que se muestra en la tabla 1 .

\section{Descripción de imágenes. Secuencias}

00:00:00 PM Carlos Pérez, director del Hospital Central de Madrid, indicando en rueda de prensa la falta de operativos sanitarios en los departamentos de urgencias.

00:00:25 PG Enfermeras y médicos con mascarillas y batas verdes en el interior de un quirófano preparando el instrumental para una operación.

00:00:31 PD Manos de técnico sanitario alineando diferentes bisturís sobre una bandeja plateada

00:00:38 PG Llegada de enfermo despierto y hablando con los camilleros y sanitarios que lo ubican sobre la mesa de operaciones. Risas y apretones de manos entre enfermo y médicos.

00:00:53 PG Fijo de la puerta de salida del quirófano de donde salen enfermeros, enfermo intubado y dormido llevado por camilleros y médicos que conversan entre ellos.

$00: 01: 15 \ldots / \ldots$

PM: Plano medio / PG: Plano general / PD: Plano detalle

Tabla 1. Descripción de imágenes

- Análisis Documental. Se realiza una doble descripción bipolarizando la labor en elementos visualizados y referenciados (onomásticos, geográficos, cronológicos y temáticos). Se observa que en los documentos audiovisuales en televisión es necesaria una doble traducción: inicialmente de la documentación audiovisual al lenguaje libre, con posterioridad dicho lenguaje se traducirá a uno controlado por medio de herramientas de control terminológico (Caldera, 2007). Debe quedar aquí reflejado que no todas las televisiones realizan este último esfuerzo de traducción (texto libre a términos de indización) derivado de la escasez de personal y por lo tanto de tiempo para su realización, por lo que esta última etapa no será llevada a cabo.

La información temática y la onomástica es la más demandada en los servicios de información, especialmente elementos iconográficos representados visualmente. En la dualidad descriptiva se identificarán los temas visionados (ejemplo: sol, montañas nevadas, ríos caudalosos, etc.) así como la significación temática de
Puntos de acceso

Visualizado / Referenciado

Temáticos

Onomásticos

Geográficos

Cronológicos

Tabla 2. Puntos de acceso en televisión

dichos iconos unidos en un mensaje periodístico (ejemplo: calentamiento de la tierra).

El usuario puede requerir tanto las noticias en su conjunto como secuencias concretas, de ahí la existencia de campos que señalen la información que se visualiza (asociada a secuencias) y aquellos términos de indización que describen el contenido temático conceptual de la información (asociados al documento). La información contenida en la banda sonora estará recogida en el campo referenciado-tema y los representados en las imágenes en visualizados-plano-tema. Cualquier información visualizada está referenciada de manera implícita. Pueden observarse ejemplos en: Caldera; Zapico, 2006.

\section{"Información onomástica, información temática visualizada y lugares físicos observados en la imagen son los tipos de información más solicitados en las televisiones"}

Información onomástica. La televisión en su pasado reciente y en su presente más actual cuenta con un periodismo declarativo; tanto es así que ver un informativo será observar declaraciones de personajes. Por ello los elementos onomásticos son importantes en la recuperación solicitada por los periodistas. Estos personajes descritos en lo visualizado normalmente hablan sobre otros personajes o instituciones, por lo que será imprescindible señalar también de quién trata la información o el protagonista referenciado.

Una entidad puede ser visionada en un documento audiovisual cuando se identifiquen más de dos miembros de un colectivo con nombre reconocido en el ejercicio de sus funciones. Este no es óbice para que sean identificados por separado en los campos que identifican a las personas físicas, siempre y cuando tengan el valor suficiente para ello.

Igualmente interesante y necesaria es la identificación de la información geográfica contenida en el documento. Información geográfica que da cabida tanto a 


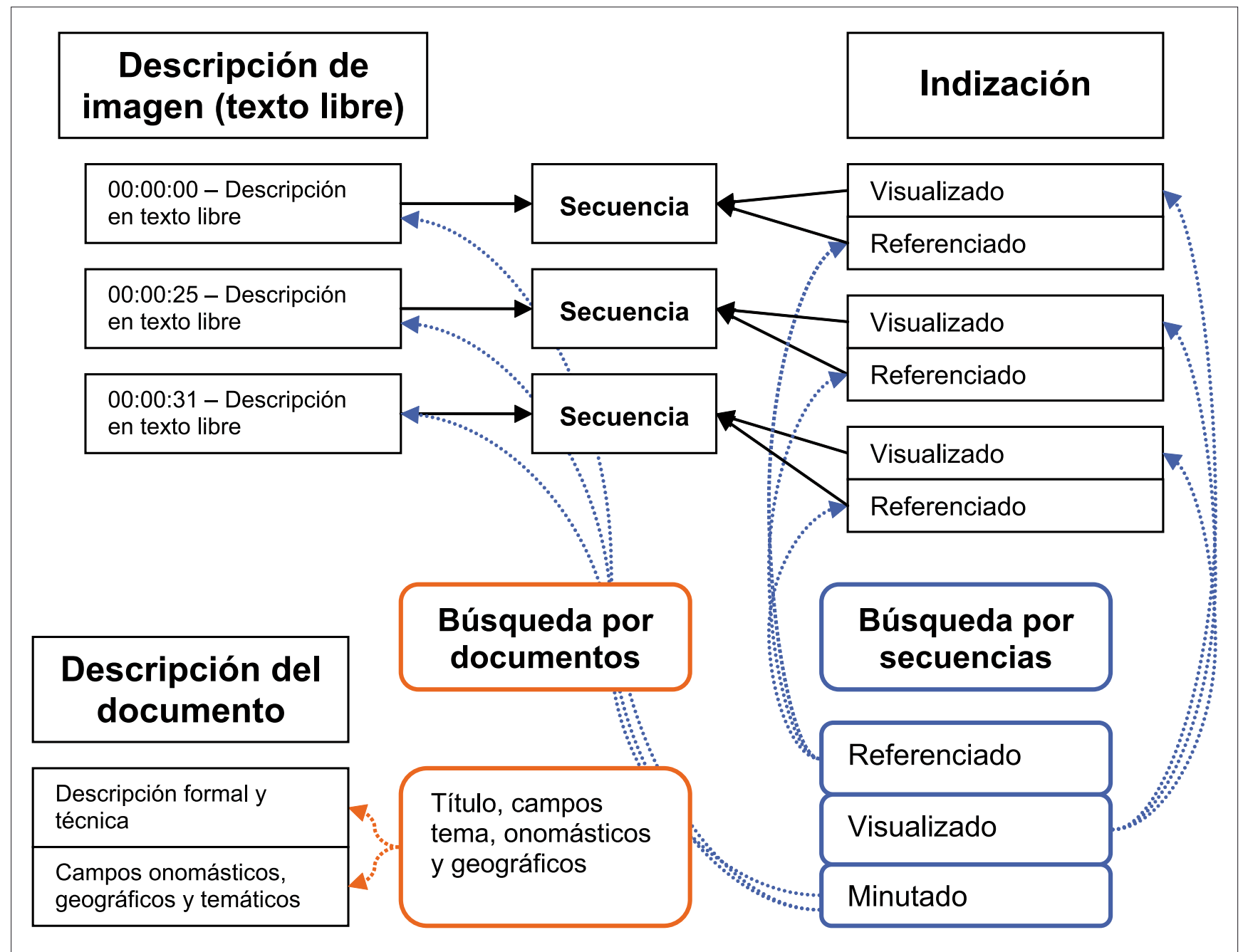

Figura 1: Campos descriptivos para la recuperación

ciudades, calles y países como a grandes zonas o accidentes geográficos. Aquí la dualidad entre lo visionado y lo referenciado también existe, aunque su importancia radica en aquellos lugares o zonas que son recuperables por su validez documental.

La información cronológica cuenta con menor interés en la recuperación, ya que será un elemento meramente discriminatorio en la consulta. Especialmente útil es la fecha de grabación de las imágenes.

En estas condiciones, lo ideal sería proporcionar la capacidad de búsqueda sobre documentos en conjunto, o sobre secuencias en concreto. Al mismo tiempo sería deseable poder llevar a cabo búsquedas sobre el nivel referenciado, el nivel visionado o el texto libre de la descripción.

\section{Rdf y rdf schema}

En una situación como la descrita anteriormente es perfectamente válido utilizar una base de datos común asociada a un sistema de recuperación de información para llevar a cabo las tareas de recuperación necesarias. Creemos que existen otras tecnologías que estando per- fectamente adaptadas a este tipo de tareas, que proporcionan valor añadido a las descripciones o cuentan con otras ventajas, y que no están siendo explotadas por ninguna televisión.

Éste es el caso de rdf y $r d f$ schema. Rdf (Resource Descripción Framework) es uno de los marcos para la representación de información orientado hacia la Web. Para no repetir lo que ya se ha explicado muchas veces nos limitaremos a decir que permite hacer descripciones estructuradas de cualquier tipo de recurso (incluyendo documentación audiovisual) ${ }^{1}$.

\section{"Rdf schema es uno de los marcos para la representación de información orientado hacia la Web"}

Rdf schema es un modelo para crear vocabularios específicos para campos de aplicación concretos ${ }^{2}$. Un schema es un documento que define estructuralmente la colección a identificar, y proporciona los campos y 
restricciones básicas para la descripción. En otras palabras, define el tipo de descripción que el documentalista hará, en nuestro caso de documentación audiovisual.

Tanto rdf como $r d f$ schema son estándares del consorcio $W 3 C$, y por lo tanto tecnologías abiertas. Más aún, constituyen la espina dorsal de la Web semántica tal y como es planteada por el $W 3 C$. Esto hace que sean tecnologías compatibles con muchas otras aplicaciones y formatos, lo que facilita la creación de servicios con valor añadido, y en general su compatibilidad con otros sistemas.

Una de las ventajas más interesantes de trabajar con rdf y rdfs es la de poder crear con rapidez herramientas para la gestión de la información. Esto se debe a la gran cantidad de librerías y aplicaciones disponibles que son compatibles con esta tecnología.

Por último, cabe señalar que las tecnologías derivadas de la Web semántica nos proporcionan la capacidad de formalizar elementos descriptivos de manera muy clara y precisa.

Por todos estos motivos, hemos de utilizar un esquema rdf para modelar el problema de la descripción de documentos audiovisuales. Detallamos los elementos del esquema a lo largo de la propuesta metodológica expuesta más adelante.

\section{Smil}

Smil es el acrónimo de Synchronized Multimedia Integration Language. Es la propuesta del consorcio W3C para la Web multimedia, y está diseñado para posibilitar la generación de documentos multimedia "puros". Actualmente ya está disponible la versión 3 de la recomendación (Bulterman, 2008).

Smil permite una integración completa con rdf, de forma que se pueden incorporar descripciones rdf a lo largo del documento multimedia tanto para referirse al conjunto del documento como para describir secuencias dentro de la estructura de smil (Pérez-Agüera, 2004).

\section{"Smil hace posible una integración completa con rdf, de forma que se pueden incorporar descripciones rdf a lo largo del documento multimedia"}

Smil hace posible la creación de documentos multimedia con una estructura compleja, e incluso la creación de descripciones de planos interactivas (Gil-Urdiciain, 2004). Sin embargo, proponemos un uso mucho más sencillo de la tecnología smil, como forma de visualización de los resultados de búsqueda y no como elemento estructural de las descripciones.

Desde este último punto de vista, lo que nos interesa es la capacidad que nos ofrece smil junto con cualquier tecnología que permita la creación de sitios web dinámicos (en nuestro caso php). Smil debe servirnos para crear el acceso a las secuencias recuperadas y visualizarlas de manera dinámica, como se podrá apreciar con posterioridad.

\section{Marcando la descripción de imágenes: propuesta metodológica.}

Hemos de partir de dos premisas para que pueda ser tomada como válida la presente propuesta metodológica:

- la correcta descripción de secuencias representa el contenido de una información audiovisual televisiva,

- el mejor método de recuperación de conceptos temáticos de información audiovisual televisiva es la utilización de palabras clave.

La primera premisa es aceptada por la práctica totalidad de los gestores de información que la incluyen en su práctica profesional. La segunda no es una realidad en todas las cadenas televisivas tal y como indicamos anteriormente.

El valor de la marcación de secuencias es que podrá integrarse la indización en la descripción y análisis de imágenes (análisis cronológico) eliminando de esta manera información superflua y facilitando el trabajo del documentalista.

\section{"Las consultas sobre la descripción de documentos audiovisuales se realizarán tanto en lenguaje controlado como por medio del texto libre de la descripción de secuencias"}

Entiéndase excesivo el esfuerzo por normalizar esos puntos de acceso en el proceso de indización cuando realmente el primer proceso descriptivo es también un momento de indización. La importancia de la descripción de secuencias y la necesidad del cambio en la forma de entender el tratamiento de la información televisiva digital está abordada de manera pormenorizada por López-de-Quintana (2007).

$\mathrm{Si}$ el documento audiovisual televisivo está bien descrito podrían recuperarse elementos anteriormente 
mencionados con búsquedas sobre texto libre o implementarlos por medio del marco con rdf para identificar estos parámetros de indización en la descripción de secuencias.

Los puntos de acceso temáticos. Evidentemente debemos plantearnos una primera cuestión. ¿Cuál de las aplicaciones existentes para la descripción, identificación y clasificación de contenido es la mejor para la descripción de material audiovisual televisivo? La primera reflexión que debemos plantearnos es que se trabaja no con conceptos sino con acciones. Las clásicas herramientas documentales como son las clasificaciones y los tesauros plantean graves problemas derivados de la naturaleza audiovisual y de su temática universal. Un tesauro generalista y universal se nos presenta como un esfuerzo ímprobo y una labor utópica, mientras que el intento de clasificación de acciones supone un esfuerzo poco afortunado.

Otro dato a tener en cuenta es el cambio de rol del gestor de información y del usuario, generado por las tecnologías de la información. Nos referimos a la proliferación de intranets corporativas. Esto provoca que el usuario acceda e interrogue directamente nuestras bases de datos sin intermediación del documentalista, por lo que cualquier tipo de aplicación dificulta el acceso de una manera rápida. Esta realidad no se escapa prácticamente a ningún campo científico ni social, pero en la labor cotidiana de los comunicadores la rapidez es un rasgo de calidad, por encima de la pertinencia y exhaustividad.

¿Qué opciones nos ofrece la realidad partiendo de la presente situación? Es la propia labor documental la que nos muestra la solución. La mayor parte de los departamentos de documentación que cuentan con intranet observan que el usuario/periodista accede directamente por texto libre al contenido temático, utilizando palabras que cree significativas, mientras que el uso de lenguaje controlado tampoco está generalizado entre los gestores de información al ser herramientas pobres ante una información de carácter universal. La recuperación utilizando palabras clave de la descripción de secuencias parece la solución.

De cualquier forma, aún se nos plantea un problema: analizando una colección de documentos audiovisuales (su descripción de secuencias) observamos que vamos a poder identificar claramente elementos onomásticos visionados y referenciados, lugares geográficos y temas visualizados. Sin embargo, el lugar de la noticia (lugar connotado y/o referenciado), fecha y temática no siempre están presentes.

La solución es la indicación de dicha información al comienzo de la descripción de secuencias de la misma forma que lo hacen los teletipos de agencia.

\section{Título documental.}

18/10/2006. Londres. Estudio científico determina que el calentamiento de la tierra provoca alteraciones que generan catástrofes naturales.

Tabla 3. Ejemplo de título documental

¿Qué solucionamos de esta manera rápida y senci1la? Indicar parámetros no siempre reseñados, además de ofrecer al usuario mayor posibilidad de recuperación en texto libre.

Hemos modelado un documento, con los campos necesarios para su adecuada descripción, dentro de un esquema $\operatorname{rdf}^{3}$.

\begin{tabular}{|c|c|}
\hline \multicolumn{2}{|c|}{ 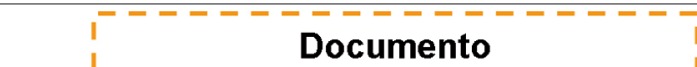 } \\
\hline Título & I \\
\hline Fecha de noticia & Codec \\
\hline Luaar de la noticia & Acceso \\
\hline Descriptores & Localización \\
\hline onomasticos genericos & Autor \\
\hline \multirow{2}{*}{$\begin{array}{l}\text { Descriptores } \\
\text { temáticos genéricos }\end{array}$} & Duración \\
\hline & I \\
\hline------ & -------- \\
\hline
\end{tabular}

Figura 2. Propiedades de un documento

Los elementos señalados en el título documental serán útiles para la recuperación de la totalidad del documento. Un documento cuenta con múltiples descripciones de secuencias, pero sólo con un título. La recuperación por un elemento del título se traduce en la recuperación del documento completo.

Los elementos que podrán ser marcados en el título, y por lo tanto serán elementos comunes, no tendrán relación directa con lo visualizado en la pieza informativa televisiva. Se cuenta con información cronológica, geográfica y temática, y potencialmente onomástica (no en todo título aparecerá un personaje).

La información presente en cada una de las descripciones se traducirá en la recuperación única de dicha secuencia si es por los términos incorporados en la descripción. La información presente podrá ser prácticamente de todo tipo: onomástica visualizada, onomástica referenciada, temática visionada, lugares visionados y en menor medida, información geográfica referenciada, temática referenciada y cronológica.

En la tabla 4 presentamos un documento con su descripción de secuencias.

Esta descripción se puede realizar de manera estructurada utilizando rdf. Para ello hemos modelado 


\section{DOCUMENTO AV}

12/12/2007. Madrid. Los servicios de urgencias de los hospitales de la Comunidad de Madrid cuentan con graves problemas de abastecimiento de material sanitario

00:00:00 PM Carlos Pérez, director del Hospital Central de Madrid, indicando en rueda de prensa la falta de operativos sanitarios en los departamentos de urgencias

00:00:25 PG Enfermeras y médicos con mascarillas y batas verdes en el interior de un quirófano preparando el instrumental para una operación

00:00:31 PD Manos de técnico sanitario alineando diferentes bisturís sobre una bandeja plateada

00:00:38 PG Llegada de enfermo despierto y hablando con los camilleros y sanitarios que lo ubican sobre la mesa de operaciones. Risas y apretones de manos entre enfermo y médicos

00:00:53 PG Fijo de la puerta de salida del quirófano de donde salen enfermeros, enfermo intubado y dormido llevado por camilleros y médicos que conversan entre ellos

$00: 01: 15 \ldots / \ldots$

PM: Plano medio / PG: Plano general / PD: Plano detalle

Tabla 4. Documento AV: Título y secuencias

las secuencias en nuestro esquema rdf de la siguiente manera:

Una descripción de secuencia utilizando rdf tendría por lo tanto el aspecto que se muestra en la tabla 5.

El procedimiento para la creación de los documentos rdf se basa en la utilización de un editor de rdf o de cualquier aplicación que pueda generarlo a partir del texto que un documentalista introduce. Esta aplicación debe proporcionar una interfaz "amigable" similar a la de cualquier sistema de gestión documental, con formularios para la introducción de los datos. En nuestro caso hemos utilizado Protégé $e^{4}$ para llevar a cabo esta tarea. La mecánica de trabajo, desde el punto de vista del documentalista, es similar a la tradicional, siendo visibles las ventajas fundamentales de esta propuesta en la fase de recuperación y no tanto en la de introducción de las descripciones en el sistema.

Para demostrar la validez del concepto hemos creado un prototipo que permite llevar a cabo el tipo de búsquedas señaladas sobre descripciones en rdf de documentos y secuencias generadas con Protégé.

\section{El prototipo}

Hemos creado un sistema para poner en práctica todas las ideas expuestas. Se puede acceder a él, incluyendo el código fuente y los esquemas y descripciones en rdf.

\section{http://buscador.rodrigosj.com.es}

El sistema implementado utiliza las descripciones en rdf de secuencias y documentos para alimentar los índices de un sistema de recuperación de información basado en Lucene $e^{5}$. Para aprovechar la estructura de las secuencias y su relación con los documentos, el índice se estructura utilizando campos.

En Lucene se utiliza un concepto atómico para la creación del índice, de manera que cada documento que se inserta en el índice está dividido en campos que incluyen el contenido sobre el que podemos en realidad hacer las búsquedas.

\begin{tabular}{|c|c|c|c|}
\hline \multicolumn{4}{|c|}{ 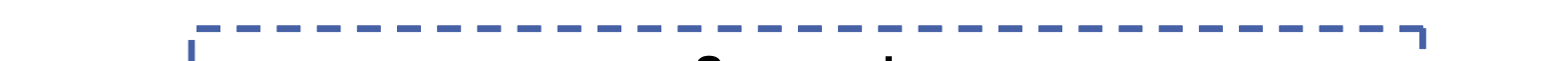 } \\
\hline I & \multicolumn{2}{|c|}{ Secuencia } & $\mathbf{I}$ \\
\hline i & \multicolumn{2}{|c|}{ Código tiempo inicio } & I \\
\hline I & \multicolumn{2}{|c|}{ Código tiempo fin } & I \\
\hline I & \multicolumn{2}{|c|}{ Referencia a documento (uri) } & I \\
\hline i & \multicolumn{2}{|l|}{ Minutado } & I \\
\hline i & \multicolumn{2}{|c|}{ Descriptores cronológicos } & I \\
\hline \multicolumn{2}{|l|}{ I } & & I \\
\hline \multicolumn{2}{|c|}{ Des. temáticos visualizados } & \multicolumn{2}{|c|}{ Des. temáticos referenciados } \\
\hline \multicolumn{2}{|c|}{ Des. geográficos visualizados } & \multicolumn{2}{|c|}{ Des. geográficos referenciados } \\
\hline \multicolumn{2}{|c|}{ Des. onomásticos jurídicos visualizados } & \multicolumn{2}{|c|}{ Des. onomásticos jurídicos referenciados } \\
\hline \multicolumn{2}{|c|}{ Des. onomásticos visualizados } & \multicolumn{2}{|c|}{ Des. onomásticos referenciados } \\
\hline
\end{tabular}

Figura 3. Propiedades de una secuencia 


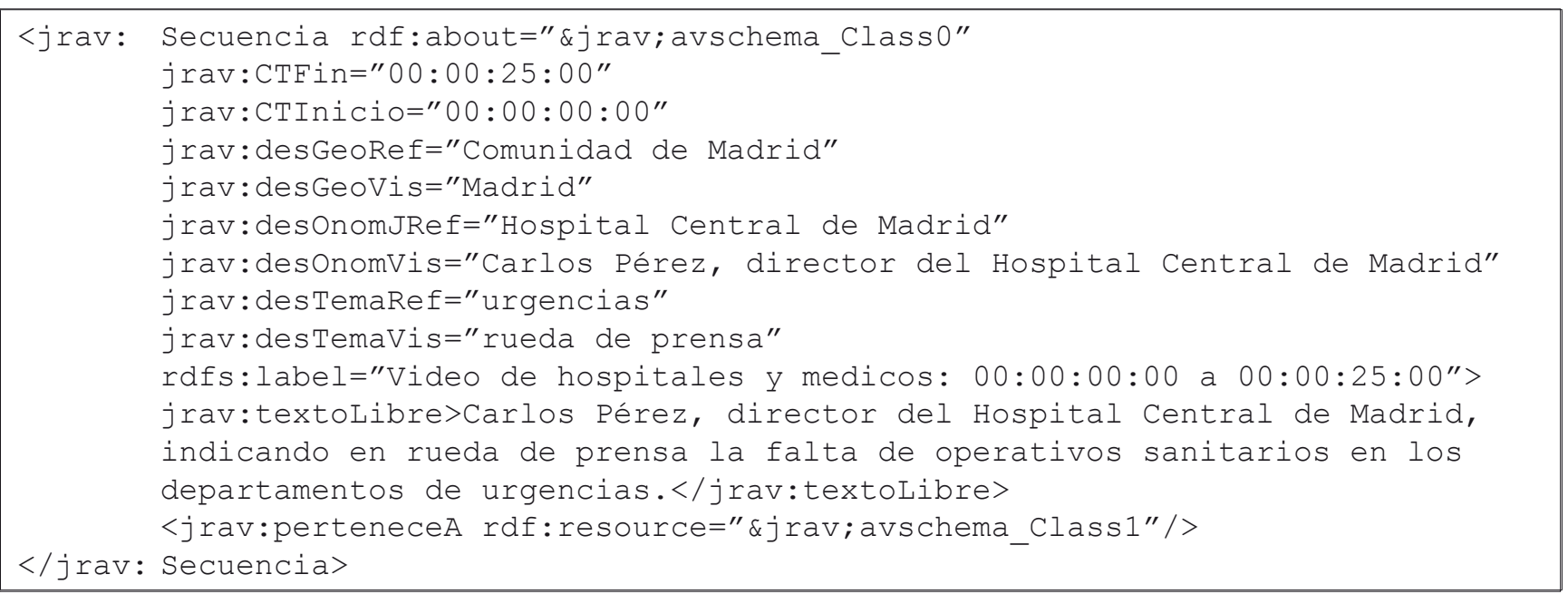

Tabla 5. Descripción rdf de lo audiovisual

Esta división en campos nos permite adaptar la búsqueda a la estructura de la información que queremos recuperar. En nuestro caso, cada una de las propiedades de un documento o de una secuencia es susceptible de ser un campo sobre el que se pueda buscar. Esto hace posible que se hayan implementado cuatro tipos dis- tintos de búsqueda: sobre toda la información del documento, sobre toda la información de las secuencias, sobre la información referenciada de las secuencias y sobre la información visualizada de las secuencias.

Por último, cuando se recupera un documento o secuencia relevante, la información relativa a los códi-

Parser I Crawler | Buscar

Secuencias

( ) Todo

Referenciado

Visualizado
Si http://thor.eubd,ucm.es/ rodrigo/buscad... $\square \square$

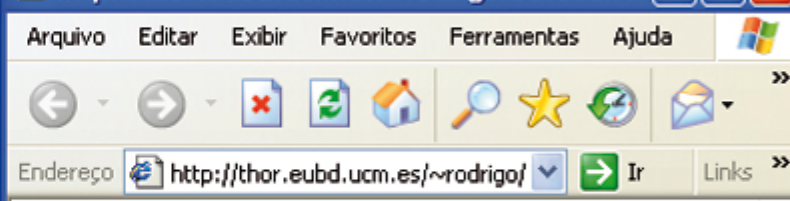

Timer:13

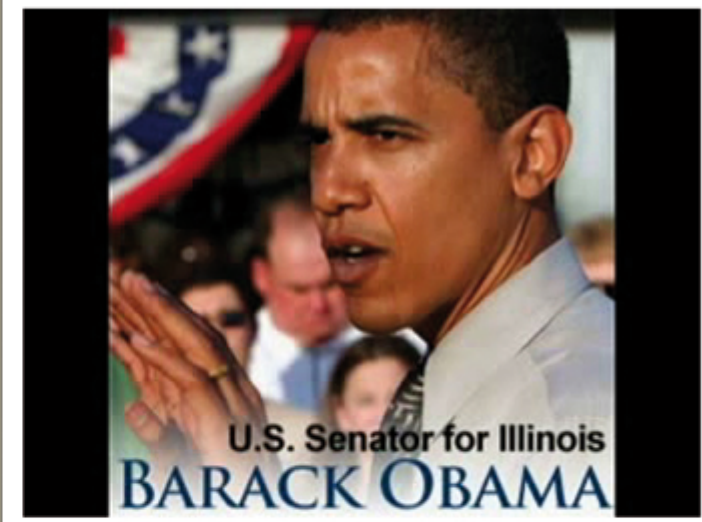

Concluido

$\mathrm{S}$

Los servicios de urgencias de los hospitales de la Comunidad de Madrid cuentan con graves problemas de abastecimiento de material sanitario 00:00:53:00-00:01:15:00

Puntuación: 0.03 


\section{"El prototipo permite adaptar la búsqueda a la estructura de la información a recuperar"}

gos de tiempo de las secuencias se utiliza para generar una presentación smil de manera dinámica. Nos hemos limitado a reproducir la secuencia desde el momento exacto de su comienzo, aunque smil ofrece muchísimas otras posibilidades, como la inserción de controles de reproducción o los enlaces hipermedia, aspectos que quedan fuera de los objetivos de este trabajo.

\section{Conclusiones}

La utilización de estas tecnologías para la recuperación no sólo de los documentos de forma completa sino también posibilitando la recuperación de secuencias, cuenta con las siguientes ventajas:

- Utilidad. La recuperación por secuencias concretas ha sido siempre uno de los fines buscados por los ingenieros y documentalistas que han creado software para los archivos audiovisuales, acortando el tiempo de respuesta y haciendo más pertinente la recuperación documental.

- Abaratamiento. Uno de los grandes problemas de los gestores de información en las televisiones ha sido la necesidad de implementar desarrollos de bases de datos "ad hoc", lo cual ha imposibilitado contar con aplicaciones ágiles y útiles para las pequeñas y medianas cadenas televisivas. La utilización de estas herramientas y su uso abre grandes posibilidades a los medios locales y, en muchos casos, autonómicos, al ser gratuitas y fácilmente accesibles.

- Intercambio. La utilización de la tecnología de marcado rdf supone la opción y el camino hacia el intercambio de información entre redes. Esto potencia la difusión y evidentemente el uso de la misma.

- Accesibilidad. La tecnología smil plantea una serie de aplicaciones y utilidades que hacen viable el acceso y la visualización de un único paquete de datos en lugar de la necesidad de ir al documento completo. La recuperación de la secuencia es sin duda un gran avance en la recuperación de información del material audiovisual, recuperando un fragmento, el deseado y el adecuado, y no todo el documento audiovisual, proceso que puede durar horas.

- Futuro. La distinción entre temas/personas/lugares tanto de lo visualizado como de lo referenciado ofrece la posibilidad de utilizar tesauros ${ }^{6}$ (información geográfica), índices (información onomástica) e incluso el uso de ontologías (Caldera, 2008) (temas/personas) para un control interno que potencie la recuperación por elementos no designados claramente en la descripción de secuencias.

\section{Notas}

1. Véase McBride, Brian (2004) para una introducción a rdf.

2. Véase: McBride, Brian (2004) para una descripción detallada de los esquemas rdf.

3. El schema rdf está disponible en:

http://buscador.rodrigosj.com.es

4. Protégé es un software gratuito creado por la Stanford University. http://protege.stanford.edu/

5. Hemos utilizado el porte a php de Lucene para este prototipo.

6. Cualquier tesauro codificado en skos-core es compatible con las descripciones en rdf, lo que facilita su integración en el sistema. La forma en que se lleve a cabo dicha integración queda, sin embargo, fuera del alcance de este artículo.

http://www.w3.org/TR/skos-referencel

\section{Referencias}

Bulterman, Dick et al. Synchronized Multimedia Integration Language (smil 3.0). Recomendación W3C, diciembre de 2008. http://www.w3.org/ TR/SMIL3/

Caldera-Serrano, Jorge. "Terminological control of 'anonymous groups' for catalogues of audiovisual television documents". Journal of librarianship and information science, 2006, v. 38, n. 3, pp. 187-196.

Caldera-Serrano, Jorge; Zapico-Alonso, Felipe. "Seen and heard: duality at the access points to television database". Aslib proceedings: New information perspectives, 2006, v. 58, n. 4, pp. 304-315.

Caldera-Serrano, Jorge; Sánchez-Jiménez, Rodrigo. "Ontología para e control y recuperación de información onomástica en televisión”. El profesional de la información, 2008, v. 17, n. 1, pp. 86-91.

Gil-Urdiciain, Blanca; Pérez-Agüera, José-Ramón; Sánchez-Jiménez, Rodrigo. "Gestión de documentación multimedia con Synchronized Multimedia Integration Language". Scire: Representación y organización del conocimiento, 2004, v. 10, n. 2, pp. 87-98.

López-de-Quintana, Eugenio. "Transición y tendencia de la documentación en televisión: digitalización y nuevo mercado audiovisual”. El profesional de la información, 2007, v. 16, n. 5, pp. 397-408.

McBride, Brian. Rdf primer. Recomendación W3C, febrero 2004. http://www.w3.org/TR/rdf-primer/

McBride, Brian. Rdf vocabulary description language 1.0: Rdf schema. Recomendación W3C, febrero 2004b. http://www.w3.org/TR/rdf-schema/

Pérez-Agüera, José-Ramón; Sánchez-Jiménez, Rodrigo; Caldera-Serrano, Jorge. "Adaptación de tecnologías stream y xml a centros de documentación en televisión". Revista española de documentación científica. 2004 , v. 27 , n. 4 , pp. 441-454.

Jorge Caldera-Serrano. Facultad de biblioteconomía y documentación. Universidad de Extremadura, Badajoz.

Plazuela de Ibn Marwan, s/n. 06071 Badajoz jcalser@alcazaba.unex.es

Rodrigo Sánchez-Jiménez. Departamento de biblioteconomía y documentación. Universidad Complutense de Madrid. Santísima Trinidad, 37. 28010 Madrid rsanchezj@ccinf.ucm.es 


\section{ProQuest}

\section{Start here...}

\section{La solución global de ProQuest en recursos de actualidad y noticias}
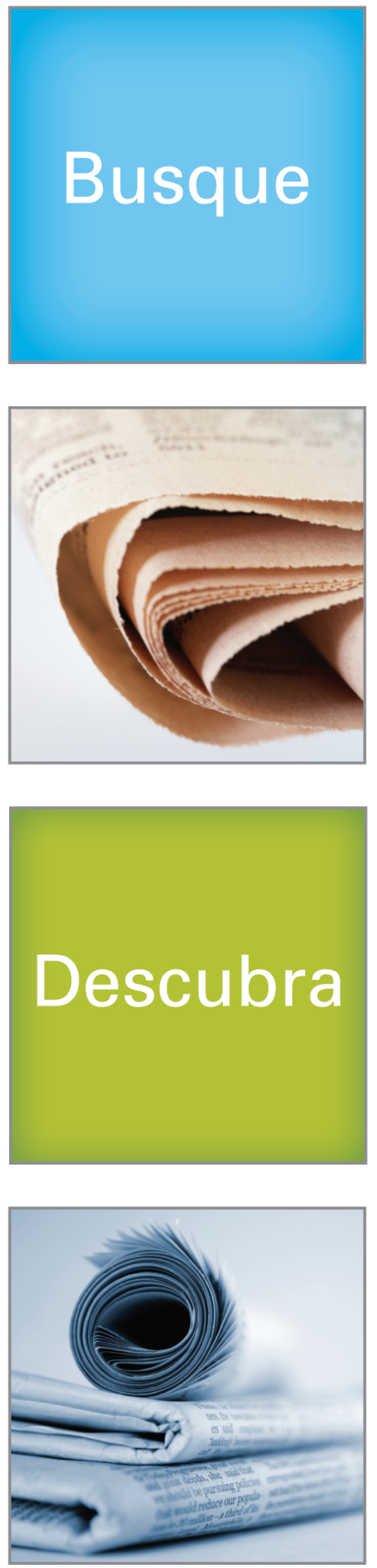
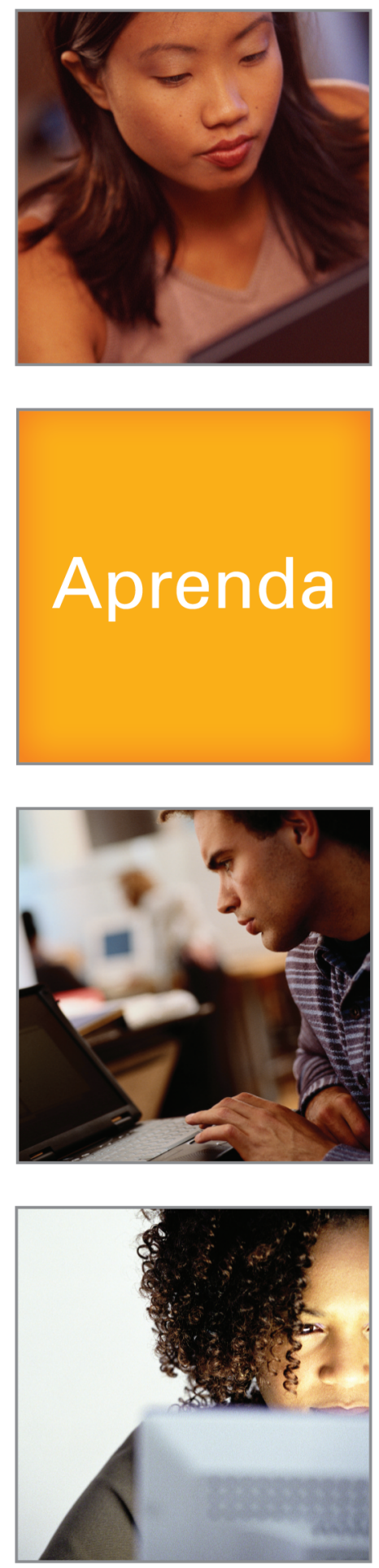

ProQuest Newsstand ${ }^{\mathrm{TM}}$

Títulos de alta calidad para la investigación y consulta.

ProQuest Newsstand permite a las bibliotecas diseñar su propia base de datos a partir de una colección de más de 500 periódicos actualizados, 350 de ellos en texto completo.

*DISPONIBLE AHORA* El Mundo en texto completo está ahora incluido en European Newsstand e International Newsstand.

NewspaperDirect PressDisplay Acceso en línea al ejemplar del día de periódicos de todo el mundo, a página completa y todo color.

Se incluyen $A B C$ y $L a$ Vanguardia.

\section{Critical Mention}

Busque y visualice videos de noticias de más de 300 cadenas de TV y estaciones de radio.

Para obtener más información o para solicitar un periodo de prueba gratuito de alguna de nuestras soluciones de actualidad y noticias, póngase en contacto con editor@iberica.proquest.com, haciendo referencia al código AD 83209. 